Disponível em:

http://editora.unoesc.edu.br/index.php/race

RACE, Joaçaba, v. 16, n. 4, p. 381-408, jan./abr. 2017

\title{
RELEVÂNCIA DA INFORMAÇÃO CONTÁBIL PARA O MERCADO BRASILEIRO DE CAPITAIS: UMAANÁLISE COMPARATIVA ENTRE LUCRO LÍQUIDO, LUCRO ABRANGENTE E FLUXO DE CAIXA OPERACIONAL
}

Value Relevance for the Brazilian capital market: a comparative analysis of Net Income, Comprehensive Income and Operating Cash Flow

Tayná Cruz Batista

E-mail: ttayna.cruzz@gmail.com

Mestre e Graduada em Ciências Contábeis pela Universidade Federal do Rio de Janeiro; Professora substituta do Departamento de Contabilidade da Faculdade de Administração em Ciências Contábeis da Universidade Federal do Rio de Janeiro.

Juliana Ferreira de Oliveira

E-mail: juliana.ffo@gmail.com

Mestre em Ciências Contábeis pela Universidade Federal do Rio de Janeiro; Graduada em Ciências Contábeis pela Universidade do Estado do Rio de Janeiro; Contadora do BNDES.

Marcelo Alvaro da Silva Macedo

E-mail: malvaro.facc.ufrj@gmail.com

Pós-doutor em Controladoria e Contabilidade pela Universidade de São Paulo; Doutor em Engenharia de Produção pela Universidade Federal do Rio de Janeiro; Professor Adjunto do Departamento de Contabilidade da Faculdade de Administração em Ciências Contábeis da Universidade Federal do Rio de Janeiro. Endereço para contato: Avenida Pedro Calmon, 550, Prédio da Reitoria, $2^{\circ}$ andar, Cidade Universitária, 21941-901, Rio de Janeiro, Rio de Janeiro, Brasil.

Artigo recebido em 05 de setembro de 2016. Aceito em 12 de dezembro de 2016. 


\section{Resumo}

Para que as informações contábeis sejam úteis às partes interessadas é necessário, entre outros aspectos, que elas sejam relevantes na revelação do desempenho organizacional. Os estudos sobre a relevância da informação contábil buscam analisar, de maneira geral, se as variações nos preços/retornos das ações guardam relação com as informações contábeis. Ou seja, verificam a relevância das informações contábeis sob a ótica dos investidores (mercado de capitais). Nesse sentido, neste trabalho buscou-se analisar se as informações contábeis são capazes de explicar as variações ocorridas no preço da ação das empresas listadas na Bolsa de Valores de São Paulo (BM\&FBovespa), utilizando o Lucro Líquido (LL), o Lucro Abrangente (LA) e o Fluxo de Caixa Operacional (FCO). A partir da base de dados Economática ${ }^{\circledR}$, foram coletadas as informações referentes ao LL, ao FCO e a Outros Resultados Abrangentes (ORAs) de 2010 a 2013. Os resultados revelam que, de maneira geral, para o mercado brasileiro de capitais, o LL se mostrou mais relevante. Em seguida, observou-se que o LA foi o mais relevante. Por outro lado, constatou-se que o FCO apresentou menor relevância; isso pode estar associado ao fato de que o lucro atende a diversas demandas, o que pode justificar maior interesse dos usuários (investidores) por essa medida de desempenho em comparação com as demais informações analisadas.

Palavras-chave: Relevância da informação contábil. Lucro Líquido. Fluxo de Caixa Operacional. Lucro Abrangente.

\section{Abstract}

For the accounting information to be useful to stakeholders, it is required, among other things, that they are relevant in the development of organizational performance. Studies on value relevance seek to analyze, in general, if the changes in prices/stock returns are related to the accounting information. So, they check the value relevance from the perspective of investors (capital markets). In this sense, this study sought to examine if the accounting information is able to explain the variations in the share price of companies listed on the São Paulo Stock Exchange (BM\&FBovespa), using Net Income (NI), Comprehensive Income (CI) and Operating Cash Flow (OCF). The information for the NI, OCF and Other Comprehensive Income (OCI) of the years 2010 to 2013 were collected from the Economática ${ }^{\circledR}$ database. The results show that, in general, for the Brazilian capital market, the NI proved to be more relevant. Then it was observed that CI is the most relevant. Moreover, it was found that the OCF showed less relevance; this may be associated with the fact that profit meets various demands, what could justify greater interest of users (investors) by that measure performance in comparison to other information analyzed.

Keywords: Value relevance. Net Profit. Operating Cash Flow. Comprehensive Income. 


\section{INTRODUÇÃO}

As pesquisas desenvolvidas com foco nos investidores buscam compreender como os relatórios contábeis influenciam o mercado de capitais. Apesar de as demonstrações contábeis reportarem informações sobre o que ocorreu no passado, a percepção do investidor será modificada quando a informação produzir reflexos no futuro (NIYAMA; SILVA, 2011).

Para fornecer informações úteis às partes interessadas sobre o desempenho de uma entidade, é necessário que as informações contábeis sejam relevantes. A informação value relevant é capaz de influenciar as decisões dos principais usuários dos relatórios financeiros. Esse atributo se faz presente no arcabouço das normas emanadas pelos órgãos reguladores. No Brasil, o Pronunciamento Contábil Estrutura Conceitual para Elaboração e Divulgação de Relatório Contábil-Financeiro (CPC 00), ao tratar das características da informação contábil relevante, destaca que “[...] informação contábil-financeira relevante é aquela capaz de fazer diferença nas decisões que possam ser tomadas pelos usuários.” (COMITÊ DE PRONUNCIAMENTOS CONTÁBEIS, 2011a, p. 4).

Ball e Brown (1968) e Beaver (1968) foram os precursores dessa abordagem de pesquisa na contabilidade, ao testarem empiricamente a associação entre o retorno das ações e o lucro contábil. Essa linha de pesquisa se insere no contexto da Teoria Positiva, pois o seu propósito é compreender o resultado produzido pela informação contábil na prática (LOPES; MARTINS, 2014). Watts e Zimmerman (1986) iniciaram a discussão sobre os fundamentos da Teoria Positiva, ao tratarem da utilidade da informação contábil.

A partir da disseminação de estudos sobre value relevance, pesquisas buscaram sistematizá-los a fim de compreendê-los, bem como confrontá-los com as bases teóricas. Holthausen e Watts (2001), Barth et al. (2001, p. 20) e Beisland (2009) examinaram a literatura sobre os estudos de value relevance. Holthausen e Watts (2001) segregaram os estudos sobre value relevance em três principais categorias: estudos de associação relativa; estudos de associação incremental e estudos de incremento de informação, concluindo que essa linha de pesquisa possui limitações para a fixação de padrões contábeis. Em contraponto ao trabalho de Holthausen e Watts (2001), Barth et al. (2001) procuraram demonstrar a contribuição dessas pesquisas para o estabelecimento de padrões. Seguindo outra trajetória, Beisland (2009) revelou os resultados dos principais estudos sobre value relevance, notadamente nos Estados Unidos, com foco nas principais informações das Demonstrações Financeiras. 
Nesse sentido, este estudo se situa no cenário da relevância da informação contábil, uma vez que se propõe a analisar a value relevance de três das principais medidas de desempenho produzidas pela contabilidade, mais especificamente do Lucro Abrangente (LA), do Lucro Líquido (LL) e do Fluxo de Caixa Operacional (FCO), examinando o poder explicativo dessas variáveis para o mercado de capitais no Brasil. O período utilizado no estudo compreende do ano 2010 ao ano 2013, considerando que a divulgação da Demonstração dos Resultados Abrangentes (DRA) foi exigida a partir do exercício social de 2010, ano de elaboração das informações contábeis conforme o padrão International Financial Reporting Standards (IFRS) para as companhias abertas.

Este trabalho justifica-se pela importância em estudar a utilidade da informação contábil como um todo. Além disso, também é uma oportunidade de examinar o resultado abrangente, medida de desempenho pouco explorada no mercado de capitais, pois foi introduzida recentemente no conjunto de Demonstrações Financeiras das companhias abertas.

A relevência deste estudo é em decorrência da importância de estudar a relação das variáveis contábeis com o preço das ações, além do contexto brasileiro, em razão do contexto de convergência às normas internacionais de contabilidade que vêm dando destaque às informações contábeis.

Assim, na presente pesquisa procurou-se responder ao seguinte questionamento: qual a relevância do LL, do LA e do FCO para o mercado brasileiro de capitais? Nesse sentido, neste trabalho teve-se como objetivo analisar comparativamente a relevância das variáveis contábeis (LL, FCO e LA) para a formação do preço das ações das empresas abertas não financeiras no período de 2010 a 2013.

Além desta seção, no trabalho aborda-se, na segunda parte, o referencial teórico relacionado às variáveis contábeis estudadas. Em seguida, apresenta-se a metodologia utilizada. Na quarta parte, os resultados são expostos e analisados, e, por fim, apresenta-se a conclusão do trabalho.

\section{REFERENCIAL TEÓRICO}

\subsection{RELEVÂNCIA DA INFORMAÇÃO CONTÁBIL}

Os primeiros estudos de value relevance utilizam um modelo que relaciona variáveis de Lucro Líquido e Patrimônio Líquido com o preço da ação das compa- 
nhias. Ball e Brown (1968) e Beaver (1968) foram os precursores dessa linha de pesquisa na contabilidade.

Os trabalhos ao longo dos anos seguem nessa linha e/ou buscam agregar outras variáveis para estudar essa relação. Burgstahler e Dichey (1997) usam um modelo para estudar o lucro e o patrimônio líquido e as adaptações feitas pelas empresas quando estas têm resultados bons ou ruins. O principal resultado é que o valor do patrimônio líquido é uma função convexa de ambos os lucros esperados e valor contábil.

O trabalho de Collins, Maydew e Weiss (1997) faz uma análise do LL e dos valores contábeis no período de 1953 a 1993. Eles encontraram que o conteúdo informacional presente nas duas variáveis não diminuiu ao longo dos anos e que as variações da relevância do LL podem ser explicadas por fatores como períodos de prejuízo, intangível e tamanho da empresa.

Barth, Beaver e Landsman (1998) partiram para uma linha diferente dos demais, eles estudaram o poder explicativo do lucro líquido nas empresas que estão com a saúde financeira ruim.

Ress (1999) estudou a relevância da informação contábil nas empresas do Reino Unido. Ele utilizou uma versão simplificada do modelo de Ohlson, com base em uma amostra composta por empresas britânicas comerciais e industriais, no período de 1987 a 1997. Os resultados variam de acordo com as características da empresa, como tamanho, dividendos e retorno sobre o patrimônio, e a alavancagem não é significativa.

Com base no exposto, nota-se que essa é uma linha de pesquisa que ainda gera espaço para a evolução do conhecimento com a utilização desses trabalhos que estudam o conteúdo informacional das variáveis contábeis, e, por conta disso, esta pesquisa se insere nessa linha.

\subsection{LUCRO ABRANGENTE, LUCRO LÍQUIDO E FLUXO DE CAIXA OPERACIONAL}

Apesar de o Resultado Abrangente ter sido efetivamente introduzido no arcabouço das normas contábeis somente em 1997, com a emissão pelo Financial Accounting Standards Board (FASB) do SFAS 130 - Reporting Comprehensive Income, a discussão sobre essa medida de desempenho entre os profissionais da classe contábil perdura desde a década de 1930. O debate sobre a melhor forma de medir o desempenho da entidade se concentrou em duas principais vertentes. Os favoráveis à utilização do resultado abrangente sustentavam que essa medida se apresenta mais adequada ao 
considerar todas as alterações dos ativos líquidos de uma entidade. Por outro lado, os grupos que defendiam o lucro operacional corrente argumentavam que considerar itens extraordinários na apuração do lucro poderia afetar a capacidade de projeção dos fluxos de caixa no longo prazo (DHALIWAL; SUBRAMANYAM; TREZEVANT, 1999, p. 44-45; CHAMBERS et al., 2007, p. 560-561).

Embora não haja um consenso sobre qual medida é mais apropriada para avaliar o desempenho de uma entidade, os órgãos reguladores de contabilidade inseriram adicionalmente o grupo "Outros Resultados Abrangentes" na lista de informações a serem divulgadas pelas companhias. Além do FASB, o Internacional Accountantig Standard Board (IASB) também disciplinou a forma de divulgação dos Resultados abrangente no IAS 1 - Presentation of Financial Statements. Por conseguinte, no Brasil, alinhado ao processo de harmonização às normas internacionais de contabilidade, o Comitê de Pronunciamentos Contábeis aprovou o Pronunciamento Contábil CPC 26 - Apresentação das Demonstrações Contábeis, o qual trata da Demonstração do Resultado Abrangente, entre outras demonstrações financeiras.

Dada a relevância do tema, o IASB incluiu um tópico relacionado à Demonstração de Resultados Abrangentes na revisão da estrutura conceitual das normas contábeis (Discussion Paper 2013/1), para que todos os interessados pudessem contribuir com comentários. Esse documento fomentou a discussão sobre a finalidade da Demonstração do Resultado Abrangente, bem como as questões que envolvem a reclassificação, também denominada "reciclagem", de determinados ajustes para o resultado.

Conforme dispõe o Pronunciamento Contábil CPC 26, “[...] resultado abrangente é a mutação que ocorre no patrimônio líquido durante um período que resulta de transações e outros eventos que não derivados de transações com os sócios na sua qualidade de proprietários.” (COMITÊ DE PRONUNCIAMENTOS CONTÁBEIS, 2011b, p. 4-5). Ainda de acordo com a referida norma, os ajustes que impactam o resultado abrangentes são: alterações na reserva de reavaliação, quando aplicáveis; planos de benefícios a empregados, conforme Pronunciamento Contábil CPC 33; variações provenientes de conversão de demonstrações contábeis em moeda estrangeira; alterações no valor dos títulos disponíveis para venda e variações de hedge de fluxo de caixa (COMITÊ DE PRONUNCIAMENTOS CONTÁBEIS, 2011b, p. 4). Em suma, os outros resultados abrangentes referem-se a receitas, despesas, ganhos e perdas ainda não realizados.

Observa-se que por conter ganhos e perdas que derivam de ajustes de valor de mercado, os componentes contabilizados como outros resultados abrangentes estão 
sujeitos à alta volatilidade. Nesse sentido, Lee e Park (2013, p. 218) ressaltam que essas informações estão submetidas ao julgamento dos administradores das empresas.

Outro ponto importante consiste na forma de apresentação dos outros resultados abrangentes nas Demonstrações Financeiras das companhias. Embora o SFAS 130 e o IAS 1 permitam a apresentação da Demonstração do Resultado Abrangente como continuação da Demonstração do Resultado do Exercício, no Brasil foi adotada a utilização específica da Demonstração dos Resultados Abrangentes (MARTINS et al., 2013), conforme detalhado no Quadro 1.

Quadro 1 - Demonstração dos Resultados Abrangentes

1. Lucro Liquido do Periodo

(+/-) 2. Outros resultados abrang entes

(+/-) 2.1 Ajustes Acumulados de conversão de moedas

(+/-) 2.2 Ganho (perdas) não realiz Investimentos disponiveis para venda

(+/-) 2.3 Hedge fluxo de caixa

(+/-) 2.4 Obrigações com Beneficios de aposentadoria

$=3$. Resultado Abrangente do periodo

Fonte: adaptado de Comissão de Valores Mobiliários (2015).

Destaca-se que os ganhos ou perdas referentes às variações das reservas de reavaliação, quando aplicáveis, e benefícios a empregados não são “reciclados”. Dessa forma, não podem ser computados no resultado do período. Por outro lado, os demais ajustes podem ser reclassificados para o resultado do período, quando da realização efetiva do ganho ou perda. Por exemplo, na ocasião de venda de títulos classificados como "disponíveis para venda", o ganho ou perda originado na transação deve ser considerado quando da apuração do resultado do período (COMITÊ DE PRONUNCIAMENTOS CONTÁBEIS, 2011b, p. 26). Nesse contexto em que se discute qual medida é mais significativa para analisar o desempenho de uma empresa, surgiram pesquisas internacionais e nacionais, as quais buscaram analisar se o resultado abrangente possui maior capacidade de explicar as variações nos retornos e/ou preço das ações em relação a outras medidas de desempenho, principalmente o lucro líquido.

Nesse sentido, Dhaliwal, Subramanyam e Trezevant (1999) estudaram o impacto do resultado abrangente para o retorno das ações. Os achados indicam que não se pode afirmar que o resultado abrangente é mais associado aos retornos das ações do que o lucro líquido. Esses resultados estão em consonância com o estudo de Kanagaretnam, Mathieu e Shehata (2009), que, ao analisarem as empresas canadenses com ações listadas no mercado americano, concluíram que o lucro líquido apresenta maior potencial para prever os fluxos de caixa futuros em relação ao lucro abrangente. Essa 
tendência também foi encontrada no estudo de Ebaid (2012), cujo resultado apontou para um maior poder explicativo do lucro líquido em relação ao lucro abrangente no mercado de capitais egípcio.

Considerando outra abordagem, a pesquisa de Pinto (2005) adotou a perspectiva de analisar a relevância dos ajustes acumulados de conversão, um dos componentes do grupo Outros Resultados Abrangentes. O autor utilizou-se do modelo adaptado de Ohlson (1995) em empresas multinacionais americanas que detinham investimentos no México ou na Alemanha. Os achados apontaram para a relevância dos ajustes acumulados de conversão.

Chambers et al. (2007) buscaram analisar se os investidores consideravam as informações contidas nos Outros Resultados Abrangentes para precificar os ativos, dividindo a análise em dois períodos: antes e após a emissão do SFAS 130. Os resultados apontaram para a relevância dos Outros resultados Abrangentes no período pós-emissão do SFAS 130. Nesse contexto, Chambers et al. (2007) entendem que outras pesquisas não indicaram a relevância dos outros resultados abrangentes em razão da utilização do período antes da obrigatoriedade de aplicação do SFAS 130.

Em sua pesquisa, Kabir e Laswad (2011) propõem analisar a qualidade dos lucros e dos resultados abrangentes das companhias listadas na Nova Zelândia, utilizando a abordagem da relevância, entre outras características da informação contábil. Os autores constataram que os resultados abrangentes não acrescentam poder explicativo ao retorno das ações. De acordo com os resultados encontrados no estudo de Lee e Park (2013), outros resultados abrangentes se mostraram mais value relevant para as companhias auditadas por empresas Big Four. Além disso, ao segregarem os componentes dos outros resultados abrangentes, os autores identificaram que os itens de avaliação mais subjetiva, como benefícios a empregados, ajustes de conversão e instrumentos derivativos, promoveram maior valorização diferencial entre empresas auditadas por Big Four, uma vez que esses itens requerem um esforço maior dos auditores para analisar as informações.

Com foco no mercado brasileiro de capitais, Curcino, Lemes e Botinha (2014) compararam os indicadores financeiros de rentabilidade, mais especificamente o Retorno sobre o Patrimônio Líquido e o Lucro por ação das companhias listadas no Índice Bovespa, utilizando o lucro líquido e o lucro abrangente. Os achados não apontaram diferenças significativas entre os indicadores de rentabilidade.

Contribuindo para a compreensão da percepção dos investidores no mercado brasileiro, Madeira e Costa Júnior (2014) analisaram o value relevance dos outros resultados abrangentes das companhias pertencentes ao Ibovespa, apoiado no modelo de Ohlson 
(1995). Foi constatado que os outros resultados abrangentes não estão associados ao valor de mercado das ações.

Nwaeze (1998) estudou a relevância do LL no ambiente regulatório, nas empresas elétricas dos Estados Unidos, para entender a relação do valor de mercado e do valor contábil das companhias. Os resultados mostraram que ao analisar a relevância do valor contábil e de itens na determinação do valor de mercado, verifica-se que a contribuição do lucro para explicar o valor de mercado diminui acentuadamente na presença do valor contábil para empresas de energia elétrica.

No que se refere às pesquisas brasileiras, vale destacar o estudo de Sarlo Neto et al. (2003), que investigaram, por meio de estudo de evento, a capacidade informacional dos Lucros Contábeis no Mercado Acionário Brasileiro no período de 1995 a 2002. O estudo constatou que a informação contábil é útil e importante para a tomada de decisões.

Outra variável importante para a informação contábil é o Fluxo de Caixa, como constatado em diversas pesquisas. Malacrida (2009) comparou a relevância do lucro e do fluxo de caixa operacional no mercado acionário brasileiro no período de 2000 a 2007. O trabalho buscou verificar a utilidade dessas variáveis para prever os fluxos de caixa futuros e o retorno das ações. Os resultados mostraram que o lucro é mais relevante para prever as informações do ano seguinte e que o FCO fornece informações relevantes para incrementar as informações fornecidas pelo lucro.

Porém, Habib (2010) comparou a relevância de uma série de indicadores contábeis de desempenho, entre os quais o fluxo de caixa operacional para o mercado australiano. Os resultados apontaram que o FCO foi sempre a informação contábil menos relevante para o período analisado.

O trabalho de Macedo et al. (2011) procurou analisar o impacto da substituição da Demonstração das Origens e Aplicações (DOAR) pela DFC, tendo como base o estudo de value relevance das informações sobre fluxo de caixa operacional e origem de recursos das operações. Os resultados mostraram que o FCO é mais relevante que as Origens de Recursos das Operações para o mercado de capitais.

Silva, Macedo e Marques (2012) buscaram estudar a relevância das informações contábeis sobre LL, Earnings Before Interest, Taxes, Depreciation and Amortization (EBITDA) e FCO para empresas do setor elétrico brasileiro no período de 2005 a 2007. Os resultados revelaram que FCO traz conteúdo informacional não contemplado pelo EBITDA.

Pode ser observado que inúmeras pesquisas relacionam essas variáveis. Assim, com base na discussão na comunidade contábil sobre o conteúdo informacional 
das medidas de desempenho, bem como nos resultados inconclusivos a respeito da relevância do resultado abrangente para os usuários da informação, neste trabalho propõe-se a estudar essas variáveis, com o diferencial de tratar do resultado abrangente.

\section{METODOLOGIA}

Este estudo pode ser caracterizado, de acordo com Gil (2010), como descritivo, visto que no presente estudo busca-se descrever se as informações contábeis são capazes de explicar as variações ocorridas no preço da ação das empresas listadas na Bolsa de Valores de São Paulo (BM\&FBovespa), utilizando LA, LL e o FCO. Em relação à abordagem, segundo Martins e Theóphilo (2009), o presente trabalho se utiliza da avaliação quantitativa, pois a partir da base de dados gerada, buscou-se organizar, caracterizar e, por fim, analisar se as informações produzidas apontam para a relação da informação contábil com o preço da ação, e, em caso afirmativo, identificar qual variável melhor explica essa relação.

A partir da base de dados Economática ${ }^{\circledR}$, foram coletadas as informações referentes ao LL, ao FCO e a Outros Resultados Abrangentes (ORA) dos anos 2010 a 2013, considerando que a divulgação das informações de acordo com o padrão contábil internacional para as companhias abertas foi exigida a partir do encerramento do exercício social de 2010, ano em que se iniciou a divulgação dos Outros Resultados Abrangentes. Além disso, seguiu-se a recomendação de Chambers et al. (2007) de que se deve focar o estudo de relevância do LA no período de sua obrigatoriedade. Para calcular o LA, somou-se o LL ao ORA. Além disso, foram obtidas as informações referentes ao preço das ações e as informações necessárias para o cálculo da quantidade de ações.

A população inicial contou com 792 observações. Considerando que foram utilizadas todas as companhias não financeiras de capital aberto contidas na base de dados da Economática ${ }^{\circledR}$, pode-se afirmar que o processo de amostragem é não probabilístico. As companhias financeiras foram excluídas da amostra, uma vez que pertencem a um mercado com regulamentação específica.

Com o propósito de compreender a relação entre a informação contábil e o preço da ação, utilizam-se as empresas com ações negociadas no mercado de valores, portanto, aquelas que não atenderam ao critério de índice de liquidez igual ou superior a 0,01 foram excluídas da amostra.

Em relação ao preço das ações, considerou-se a primeira cotação disponível para a empresa nas datas de 30 de abril a 05 de maio nos anos das publicações das 
demonstrações contábeis. As empresas que não apresentaram informações sobre as cotações, no período sob análise, foram eliminadas da amostra.

A fim de eliminar os valores mais extremos, foram excluídos da base de dados os 15 maiores e os 15 menores valores de cada variável independente, que correspondem a 2,5\% de cada lado da cauda. Essa técnica para tratamento de outliers é conhecida como winsorização e foi utilizada por Novaes (2015). A amostra final para a análise de 2010 a 2013 foi formada por 587 unidades de observação, trazendo uma média de aproximadamente 147 empresas por ano. Adicionalmente, a quantidade de ações foi utilizada para encontrar as informações do Lucro Líquido por Ação (LLPA), Fluxo de Caixa Operacional por Ação (FCOPA) e Lucro Abrangente por Ação (LAPA).

Tendo por base que o mercado brasileiro de ações apresenta sinais de eficiência e, portanto, considera as informações públicas para estabelecer os preços dos ativos transacionados (MACEDO; ROMANA; SILVA, 2014), bem como os trabalhos de Sarlo Neto et al. (2003), Malacrida (2009), Macedo et al. (2011) confirmam a relevância de medidas de desempenho contábeis para o mercado brasileiro de ações, apresenta-se a seguinte hipótese de pesquisa:

H1: O LL, o LA e o FCO são estatisticamente significativos para a formação do preço da ação e estão relacionados positivamente com o preço das ações das companhias abertas do setor não financeiro no mercado brasileiro de capitais.

Além disso, estudos realizados sobre o conteúdo informacional das perdas apontam que os prejuízos são menos relevantes para os investidores, dado que as perdas podem estar relacionadas aos eventos transitórios. Beisland (2009) defende que o prejuízo tem um menor poder informacional, já que os investidores têm sempre a situação de lucro como algo normal e o prejuízo como algo temporário. Os estudos de Hayn (1995), Habib e Azim (2008) e Filip e Raffournier (2010) seguem na mesma linha. Por conta disso, é importante verificar o comportamento da informação contábil na formação do preço da ação quando as empresas apresentam resultados negativos. Dessa forma, surge a seguinte hipótese:

H2: Os resultados positivos para o LL, o LA e o FCO apresentam maior poder explicativo sobre o preço das ações das companhias abertas do setor não financeiro no mercado brasileiro de capitais quando comparados com a amostra que envolve resultados positivos e negativos. 
Com o objetivo de verificar se o comportamento das variáveis contábeis é capaz de explicar o comportamento dos preços das ações, foi utilizada a análise de regressão. Assim, foram empilhados os dados das empresas ano a ano, por meio do modelo pooling.

Para desenvolver o propósito do estudo, foram utilizados três modelos de análise de regressão simples, utilizando o preço da ação e cada uma das variáveis contábeis, com base na adaptação dos modelos econométricos apresentados nas pesquisas de Collins, Maydew e Weiss (1997), Habib (2010) e Ebaid (2012).

Os modelos utilizados nos estudos foram:

$$
\begin{aligned}
& \mathrm{P}_{\mathrm{i}, \mathrm{t}}=\alpha_{0}+\alpha_{3} \mathrm{LAPA}_{\mathrm{i}, \mathrm{t}}+\varepsilon \mathrm{i}_{, \mathrm{t}} \\
& \mathrm{P}_{\mathrm{i}, \mathrm{t}}=\alpha_{0}+\alpha_{1} \mathrm{LLPA}_{\mathrm{i}, \mathrm{t}}+\varepsilon \mathrm{i}, \\
& \mathrm{P}_{\mathrm{i}, \mathrm{t}}=\alpha_{0}+\alpha_{2} \mathrm{FCOPA}_{\mathrm{i}, \mathrm{t}}+\varepsilon_{\mathrm{i}, \mathrm{t}}
\end{aligned}
$$

Em que:

$\mathrm{P}_{\mathrm{i}, \mathrm{t}}=$ Variável dependente, representada pelo preço da ação da empresa i, no tempo t;

$\alpha_{0}=$ Intercepto;

$\alpha_{1}=$ Coeficiente de inclinação para o LLPA;

$\alpha_{2}=$ Coeficiente de inclinação para o FCOPA;

$\alpha_{3}=$ Coeficiente de inclinação para o LAPA.

$L L P A=$ Variável independente, representada pela divisão do Lucro Líquido (LL) advindo da Demonstração do Resultado do Exercício (DRE) pelo número de ações da empresa $i$, no tempo $t$;

FCOPA = Variável independente, representada pela divisão do Fluxo de Caixa Operacional (FCO) advindo da Demonstração dos Fluxos de Caixa (DFC) pelo número de ações da empresa $i$, no tempo $t$;

LAPA = Variável independente, representada pela divisão do Lucro Abrangente (LA), obtido por meio da soma do Lucro Líquido com os Outros Resultados Abrangentes do período, pelo número de ações da empresa $i$, no tempo $t$. 
Para operacionalizar o estudo, procedeu-se ao desenvolvimento das seguintes etapas: analisar se a informação contábil é relevante para o mercado de ações por meio das equações 1, 2 e 3; e comparar se os resultados positivos relativos ao LL, LA e FCO apresentam maior poder explicativo em relação aos resultados obtidos considerando a amostra total. Nesse sentido, utilizaram-se essas etapas para a análise das subamostras considerando a base de dados total e, também, as unidades de análise que apresentaram LA diferente de LL, conforme descrito na Tabela 1.

A análise também envolveu o coeficiente de determinação, representado pelo $\mathrm{R}^{2}$, que demonstra a capacidade explicativa do modelo (FÁVERO et al., 2009). Como o presente estudo irá comparar os três modelos de regressão já apresentados, foi utilizado o $\mathrm{R}^{2}$ ajustado para fins de análise.

Tabela 1 - Amostras da pesquisa

\begin{tabular}{lrr}
\hline \multicolumn{1}{c}{ Descrição amostra } & \multicolumn{2}{c}{ Unidades de análise } \\
\hline & Base Total & Base das empresas que apresentaram \\
ORA $\neq 0$
\end{tabular}

Para utilizar o modelo de regressão, alguns pressupostos devem ser atendidos. O pressuposto relativo à normalidade dos resíduos foi verificado por meio do teste Jarque-Bera (JB). Para a homocedasticidade dos resíduos, utilizou-se o teste de Breusch-Pagan-Godfrey (BPG). Para os casos em que se encontrou o problema da heterocedasticidade dos resíduos, utilizou-se a correção de White, que, segundo Gujarati (2006), corrige os erros-padrão dos coeficientes, tornando-os consistentes para a heterocedasticidade.

Todos os testes foram executados no Gretl 1.9.14, em que também foram feitas as análises de regressão, considerando-se sempre o nível de significância de 1\%. 


\section{RESULTADOS}

\subsection{ANÁLISE DO CONTEÚDO INFORMACIONAL DOS MODELOS}

A Tabela 2 apresenta o modelo que relaciona o preço da ação com o lucro líquido. O modelo apresentado mostrou-se estatisticamente significativo, uma vez que a estatística $\mathrm{F}$ indicou um p-valor menor que 0,01. Essa conclusão também pode ser estendida para a análise do coeficiente relativo ao lucro líquido por ação, já que a regressão possui apenas uma variável independente. Assim, o coeficiente da variável LLPA é positivo e estaticamente significativo pois o p-valor do teste $t$ é menor que 0,01. Com isso, observa-se que o Lucro Líquido por Ação tem poder explicativo no preço da ação, e que 39,88\% da variação no preço da ação é explicada pela variação no lucro líquido.

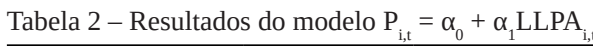

\begin{tabular}{|c|c|c|c|c|c|}
\hline \multicolumn{6}{|c|}{ Painel A } \\
\hline $\begin{array}{l}\text { Variável indepen- } \\
\text { dente }\end{array}$ & Coeficiente & Coef. padronizado & Erro-padrão & Razão-t & P-valor \\
\hline const & 11,2158 & 0 & 0,52071 & 21,5393 & $<0,00001$ \\
\hline LLPA & 6,73831 & 0,631508 & 0,560426 & 12,0236 & $<0,00001$ \\
\hline \multicolumn{6}{|c|}{ Painel B } \\
\hline $\mathrm{R}^{2}$ & 0,398802 & & & $\mathrm{R}^{2}$ ajustado & 0,397774 \\
\hline$F(1,585)$ & 144,5658 & & & P-valor(F) & $6,51 \mathrm{E}-30$ \\
\hline
\end{tabular}

Fonte: os autores.

A Tabela 3 apresenta o modelo de regressão que busca relacionar o preço da ação e o fluxo de caixa operacional por ação. Esse modelo pretende verificar se a variação no fluxo de caixa é capaz de explicar o comportamento do preço da ação. O modelo apresentou-se estatisticamente significativo, considerando que o teste F apontou um p-valor inferior a 0,01. Além disso, pode-se concluir que 26,15\% da variação no preço da ação é em razão da variação no fluxo de caixa da empresa, visto que o $\mathrm{R}^{2}$ é de 0,2615 . 
Tabela 3 - Resultados do modelo $\mathrm{P}_{\mathrm{i}, \mathrm{t}}=\alpha_{0}+\alpha_{2} \mathrm{FCOPA}_{\mathrm{i}, \mathrm{t}}$

\begin{tabular}{llllll}
\hline \multicolumn{5}{c}{ Painel A } \\
$\begin{array}{llllll}\text { Variável indepen- } \\
\text { dente }\end{array}$ & Coeficiente & Coef. padronizado & Erro-padrão & Razão-t & P-valor \\
Const & 11,0137 & 0 & 0,550277 & 20,0149 & $<0,00001$ \\
FCOPA & 4,01842 & 0,511374 & 0,375644 & 10,6974 & $<0,00001$ \\
\hline \multicolumn{7}{c}{ Painel B } \\
\hline $\mathrm{R}^{2}$ & 0,261503 & $\mathrm{R}^{2}$ ajustado & 0,260241 \\
$\mathrm{~F}(1$, 585) & 114,4343 & P-valor(F) & $1,63 \mathrm{E}-24$ \\
\hline Fonte: 0S autores. & & & &
\end{tabular}

A Tabela 4 apresenta o modelo em que a variável dependente é representada pelo preço da ação e a variável independente compreende o lucro abrangente. Dessa forma, o modelo busca explicar se a variação no lucro abrangente de uma empresa é capaz de explicar a variação no preço da ação.

Tabela 4 - Resultados do modelo $\mathrm{P}_{\mathrm{i}, \mathrm{t}}=\alpha_{0}+\alpha_{3} \mathrm{LAPA}_{\mathrm{i}, \mathrm{t}}$

\begin{tabular}{llllll}
\hline \multicolumn{5}{c}{ Painel A } \\
\hline $\begin{array}{l}\text { Variável indepen- } \\
\text { dente } \\
\text { const }\end{array}$ & Coeficiente & Coef. padronizado & Erro-padrão & Razão-t & P-valor \\
LAPA & 11,3103 & 0 & 0,522379 & 21,6516 & $<0,00001$ \\
\hline \multicolumn{7}{c}{ Painel B } & 0,473447 & 9,7007 & $<0,00001$ \\
\hline $\mathrm{R}^{2}$ & 4,59278 & 0,551301 & & 0,302743 \\
$\mathrm{~F}(1,585)$ & 0,303933 & $\mathrm{R}^{2}$ ajustado & $9,88 \mathrm{E}-21$ \\
\hline
\end{tabular}

O modelo como um todo mostrou-se significativo, pois o p-valor do teste $\mathrm{F}$ foi inferior a 0,01. Além disso, a variável independente lucro abrangente também se apresentou significativa, com p-valor do teste menor que 0,01. Dessa forma, pode-se concluir que a variação do lucro abrangente promove impacto no preço da ação. $\mathrm{O}$ coeficiente de determinação $\left(\mathrm{R}^{2}\right)$ para o modelo sob análise é de 0,3039 . Isso mostra que 30,39\% da variação do preço da ação é em razão da variação do lucro abrangente.

Para os três modelos, o teste de normalidade dos resíduos apresentou rejeição da hipótese nula. Entretanto, com base no Teorema do Limite Central e considerando que a amostra abrange 587 unidades de análise, o pressuposto pode ser relaxado, conforme indica Brooks (2002) e Corrar, Paulo e Dias Filho (2007). Adicionalmente, foi aplicada a correção dos erros-padrão robustos, pois a hipótese nula de homocedasticidade das variâncias dos erros foi rejeitada nos três modelos. 
Assim, os três modelos apresentaram-se estatisticamente significativos, ao nível 1\% de significância. Para identificar qual modelo possui maior capacidade explicativa, identificou-se o modelo que apontou maior coeficiente de determinação (R2) ajustado.

A partir da análise dos resultados, observa-se que o modelo mais relevante para a formação do preço da ação é o modelo 1, o qual utiliza a variável LLPA, pois apresentou um R2 ajustado de 39,77\%. O segundo modelo mais relevante para a formação do preço da ação foi o modelo do Lucro Abrangente, que apresentou um R2 ajustado de 30,27\%. Por fim, o modelo que apresentou menor relevância na formação do preço da ação foi o modelo do Fluxo de Caixa Operacional, apresentando um R2 ajustado de $26,02 \%$.

Esses resultados vão ao encontro dos trabalhos de Malacrida (2009) e Habib (2010), que concluíram que o FCO tem um menor poder informacional quando comparado ao LL. Os trabalhos de Burgstahler e Dichey (1997), Collins, Maydew e Weiss (1997), Barth, Beaver e Landsman (1998) e Sarlo Neto et al. (2003) confirmam a relevância do LL, encontrando que essa medida é a que tem maior poder informacional do preço das ações.

Com o objetivo de comparar os coeficientes angulares das três variáveis independentes estudadas, foi efetuada a padronização dessas variáveis. Nas Tabelas 2, 3 e 4 são apresentados os coeficientes padronizados. A partir das informações apresentadas, verifica-se que uma unidade de variação no lucro líquido por ação explica uma variação de 0,63 no preço da ação; uma unidade de variação no fluxo de caixa operacional por ação explica uma variação de 0,51 no preço da ação; e uma unidade de variação no lucro abrangente por ação explica uma variação de 0,55 no preço da ação. Portanto, a variação do preço da ação é mais sensível à variação do lucro líquido por ação.

Como visto anteriormente, Beisland (2009) defende que o prejuízo tem um menor poder informacional, já que os investidores têm sempre a situação de lucro como algo normal e o prejuízo como algo temporário. Diante disso, torna-se necessário estudar a amostra excluindo os valores negativos. Os estudos de Hayn (1995), Habib e Azim (2008) e Filip e Raffournier (2010) seguem na mesma linha. A análise apenas dos resultados negativos de LL, FCO e LA não foi feita nessa pesquisa por conta de as variáveis não terem sido estatisticamente significativas nem a 5\%. Os autores mencionados defendem que os resultados positivos têm um melhor poder informacional; o direcionamento das análises deste artigo está em linha com a literatura. 
A Tabela 5 apresenta os resultados de todas as regressões diante da exclusão dos valores negativos. Observa-se que os três modelos são estatisticamente significativos com p-valor do teste $\mathrm{F}$ inferior a $1 \%$.

Em relação ao coeficiente de determinação (R2) ajustado, verificou-se que o maior valor encontrado foi de 0,4159, o qual corresponde ao R2 ajustado da variável LLPA. Por outro lado, o menor valor observado foi de 0,2184, referente à variável FCOPA. Assim, quando são considerados apenas os valores positivos para análise, a variável LLPA é a que tem maior poder explicativo do preço da ação, e a variável FCOPA é a que tem o menor poder informacional em relação ao preço da ação.

Tabela 5 - Resultados dos modelos com a exclusão das observações negativas

\begin{tabular}{|c|c|c|c|c|c|c|c|c|c|}
\hline $\begin{array}{l}\text { Mo- } \\
\text { delo }\end{array}$ & $\begin{array}{l}\text { Variá- } \\
\text { vel in- } \\
\text { depen- } \\
\text { dente }\end{array}$ & $\begin{array}{l}\text { Coefi- } \\
\text { ciente }\end{array}$ & $\begin{array}{c}\text { Erro-pa- } \\
\text { drão }\end{array}$ & Razão-t & P-valor & $\mathbf{F}$ & $\begin{array}{c}\text { P-valo- } \\
\text { r(F) }\end{array}$ & R2 & $\begin{array}{c}\text { R2 ajus- } \\
\text { tado }\end{array}$ \\
\hline \multirow[t]{2}{*}{1} & const & 8,47303 & 0,853294 & 9,9298 & $<0,00001$ & \multirow{2}{*}{110,0548} & $3,01 \mathrm{E}-$ & \multirow{2}{*}{0,417205} & \multirow{2}{*}{0,415949} \\
\hline & LLPA & 8,56385 & 0,816328 & 10,4907 & $<0,00001$ & & 023 & & \\
\hline \multirow[t]{2}{*}{2} & const & 10,8743 & 0,835781 & 13,011 & $<0,00001$ & \multirow{2}{*}{76,22118} & $4,27 \mathrm{E}-$ & \multirow{2}{*}{0,220071} & \multirow{2}{*}{0,218439} \\
\hline & FCOPA & 4,13238 & 0,473328 & 8,7305 & $<0,00001$ & & 017 & & \\
\hline \multirow[t]{2}{*}{3} & const & 11,5336 & 0,897588 & 12,8495 & $<0,00001$ & \multirow{2}{*}{53,32694} & $1,20 \mathrm{E}-$ & \multirow{2}{*}{0,243775} & \multirow{2}{*}{0,242186} \\
\hline & LAPA & 4,608 & 0,631014 & 7,3025 & $<0,00001$ & & 012 & & \\
\hline
\end{tabular}

Fonte: os autores.

Quando se comparam os $\mathrm{R}^{2}$ ajustados do modelo da primeira análise com os $\mathrm{R}^{2}$ ajustados da análise das observações positivas, nota-se que a variável LLPA apresentou o $\mathrm{R}^{2}$ ajustado para os valores positivos maior do que o $\mathrm{R}^{2}$ ajustado considerando todas as observações. Contudo, o $\mathrm{R}^{2}$ para as observações positivas das variáveis FCOPA e LAPA é menor que o $\mathrm{R}^{2}$ que considera todas as observações.

A correlação entre a variável LL e FCO foi de 0,5529. Já a correlação entre o LL e o LA foi de 0,8098. A correlação entre o FCO e o LA foi de 0,5443. Assim, nota-se que as variáveis estão altamente correlacionadas, razão pela qual não foi utilizada uma regressão múltipla com as três variáveis neste trabalho. 


\subsection{ANÁLISE SOMENTE DAS EMPRESAS QUE APRESENTARAM O LUCRO LÍQUIDO DIFERENTE DO LUCRO ABRANGENTE}

Nesta subseção buscou-se analisar o conteúdo informacional do modelo caso a amostra fosse reduzida para apenas as empresas que divulgaram seu Lucro Líquido, sendo este diferente do Lucro Abrangente. Ou seja, foram excluídas da análise as observações que apresentaram Outros Resultados Abrangentes iguais a zero. Considerando que a parcela de Outros Resultados Abrangentes corresponde a um ganho/perda não realizado e que em um momento futuro irá para o resultado, a intenção com esta análise é verificar o conteúdo informacional da variável nessas empresas que contabilizaram lucros não realizados no período estudado.

A amostra inicialmente composta por 587 observações foi reduzida para 376 observações. O modelo que usa o Lucro Líquido continua significativo, e o poder explicativo da variável aumentou com essa redução da amostra. Inicialmente era de $39,88 \%$ e aumentou para 42,44\%. Na Tabela 6 são expostos os resultados do modelo que utiliza o Lucro Líquido como variável independente.

Tabela 6 - Resultados do modelo $\mathrm{P}_{\mathrm{i}, \mathrm{t}}=\alpha_{0}+\alpha_{1} \mathrm{LLPA}_{\mathrm{i}, \mathrm{t}}$

\begin{tabular}{llllll}
\hline \multicolumn{7}{c}{ Painel A } \\
\hline Variável independente & Coeficiente & Coef. padronizado & Erro-padrão & Razão-t & P-valor \\
Const & 11,7567 & 0 & 0,648188 & 18,1378 & $<0,00001$ \\
LLPA & 6,61046 & 0,651527 & 0,646474 & 10,2254 & $<0,00001$ \\
\hline \multicolumn{7}{c}{ Painel B } \\
\hline $\mathrm{R}^{2}$ & 0,424487 & $\mathrm{R}^{2}$ ajustado & & 0,422948 \\
$\mathrm{~F}(1,374)$ & 104,5591 & P-valor(F) & & $8,33 \mathrm{E}-22$ \\
\hline Fonte: OS autores & & & &
\end{tabular}

O modelo que se utiliza da variável do Fluxo de Caixa Operacional também se mostra significativo, além de ter tido melhora em seu poder explicativo. Com a amostra de 587 empresas, o R2 era de 26,15\% e com a amostra de 376 observações foi de $29,73 \%$. Na Tabela 7 são expostos os resultados do modelo. 
Tabela 7 - Resultados do modelo $\mathrm{P}_{\mathrm{i}, \mathrm{t}}=\alpha_{0}+\alpha_{1} \mathrm{FCOPA}_{\mathrm{i}, \mathrm{t}}$

\begin{tabular}{lrrrrr}
\hline \multicolumn{5}{c}{ Painel A } \\
\hline Variável independente & Coeficiente & Coef. padronizado & Erro-padrão & Razão-t & \multicolumn{1}{l}{ P-valor } \\
Const & 10,2448 & 0 & 0,704994 & 14,5318 & $<0,00001$ \\
FCOPA & 4,10168 & 0,545279 & 0,370139 & 11,0814 & $<0,00001$ \\
\hline \multicolumn{5}{c}{ Painel B } \\
\hline $\mathrm{R}^{2}$ & 0,297329 & $\mathrm{R}^{2}$ ajustado & & 0,29545 \\
$\mathrm{~F}(1$, 374) & 122,7985 & P-valor(F) & $7,19 \mathrm{E}-25$ \\
\hline Fonte: os autores. & & & &
\end{tabular}

Fonte: os autores.

Assim como os outros modelos, o modelo do Lucro Abrangente também se mostrou significativo. Porém, foi o que teve menor incremento de $\mathrm{R}^{2}$. Inicialmente, com 30,39\% de explicação, passou para 30,64\%. A Tabela 8 traz os resultados do modelo.

Adicionalmente, as variáveis foram padronizadas, a fim de comparar os coeficientes dos três modelos. Nas Tabelas 6, 7 e 8, pode-se observar os coeficientes padronizados. Diante do exposto, nota-se que uma unidade de variação no lucro líquido por ação explica uma variação de 0,6515 no preço da ação. Já uma unidade de variação no fluxo de caixa operacional por ação explica uma variação de 0,5452 no preço da ação, e uma unidade de variação no lucro abrangente por ação explica uma variação de 0,5535 no preço da ação. Observa-se que todas as variáveis provocam uma variação diretamente proporcional ao preço da ação. Um aumento nas variáveis estudadas gera um aumento no preço da ação, e um decréscimo nas variáveis estudadas traz uma queda no preço da ação. Além disso, diante dos resultados apresentados, pode-se observar que a variação do preço da ação é mais sensível à variação do lucro líquido por ação.

Tabela 8 - Resultados do modelo $\mathrm{P}_{\mathrm{i}, \mathrm{t}}=\alpha_{0}+\alpha_{1} \mathrm{LAPA}_{\mathrm{i}, \mathrm{t}}$

\begin{tabular}{|c|c|c|c|c|c|}
\hline \multicolumn{6}{|c|}{ Painel A } \\
\hline Variável independente & Coeficiente & Coef. padronizado & Erro-padrão & Razão-t & P-valor \\
\hline Const & 11,3879 & 0 & 0,665998 & 17,099 & $<0,00001$ \\
\hline LAPA & 4,08771 & 0,553545 & 0,523307 & 7,8113 & $<0,00001$ \\
\hline \multicolumn{6}{|c|}{ Painel B } \\
\hline $\mathrm{R}^{2}$ & 0,306412 & $\mathrm{R}^{2}$ ajustado & & & 0,304557 \\
\hline $\mathrm{F}(1,374)$ & 122,7985 & P-valor(F) & & & 5,77E-14 \\
\hline
\end{tabular}

Conforme já mencionado, é importante verificar como ocorre o comportamento das unidades de análises quando são excluídos os resultados negativos. Em 
seus trabalhos, Hayn (1995), Habib e Azim (2008) e Filip e Raffournier (2010) defendem que o prejuízo tem menor poder informacional.

A análise apenas dos resultados negativos de LL, FCO e LA não foi incluída, pois os três modelos não foram estatisticamente significativos. Conforme já dito que os resultados positivos têm um melhor poder informacional, o direcionamento das análises deste artigo está em linha com a literatura.

Assim, buscou-se verificar se há diferença significativa nos resultados considerando apenas os valores positivos para os modelos que consideram todas as observações e os modelos que usam a amostra contendo apenas as empresas que apresentaram o LL diferente do LA.

A Tabela 9 apresenta os resultados dos modelos que foram rodados com a exclusão dos valores negativos. Os três modelos são estatisticamente significativos com p-valor do teste F inferior a 1\%. Nota-se que o comportamento das três variáveis divergiu um pouco dos modelos que deram início a essa seção, bem como dos modelos apresentados na seção 4.1. Com essa nova amostra, verificou-se que o maior valor encontrado para o R2 ajustado continua sendo o da variável LLPA, com R2 ajustado de 0,4784 . Porém, o LAPA passou a ser a variável com menor poder explicativo, pois é capaz de explicar 24,19\% da variação no preço da ação.

Tabela 9 - Resultados dos modelos com a exclusão das observações negativas

\begin{tabular}{|c|c|c|c|c|c|c|c|c|c|}
\hline $\begin{array}{l}\text { Mo- } \\
\text { delo }\end{array}$ & $\begin{array}{c}\text { Va- } \\
\text { riável } \\
\text { inde- } \\
\text { pen- } \\
\text { dente }\end{array}$ & $\begin{array}{l}\text { Coefi- } \\
\text { ciente }\end{array}$ & $\begin{array}{l}\text { Erro-pa- } \\
\text { drão }\end{array}$ & Razão-t & P-valor & $\mathbf{F}$ & P-valor(F) & $\mathbf{R} 2$ & $\begin{array}{c}\text { R2 ajus- } \\
\text { tado }\end{array}$ \\
\hline \multirow{2}{*}{1} & const & 7,94147 & 1,05549 & 7,5239 & $<0,00001$ & \multirow{2}{*}{89,3758} & \multirow{2}{*}{ 1,13E-018 } & \multirow{2}{*}{0,48023} & \multirow{2}{*}{0,47844} \\
\hline & LLPA & 9,0432 & 0,95656 & 9,4539 & $<0,00001$ & & & & \\
\hline \multirow{2}{*}{2} & const & 9,63425 & 0,95682 & 10,069 & $<0,00001$ & \multirow{2}{*}{96,6176} & \multirow{2}{*}{$5,20 \mathrm{E}-020$} & \multirow{2}{*}{0,26638} & \multirow{2}{*}{0,263999} \\
\hline & FCOPA & 4,36204 & 0,44377 & 9,8294 & $<0,00001$ & & & & \\
\hline \multirow{2}{*}{3} & const & 11,49 & 1,17108 & 9,8114 & $<0,00001$ & \multirow{2}{*}{33,4074} & \multirow{2}{*}{ 1,85E-008 } & \multirow{2}{*}{0,24444} & \multirow{2}{*}{0,241955} \\
\hline & LAPA & 4,10704 & 0,71057 & 5,7799 & $<0,00001$ & & & & \\
\hline
\end{tabular}

Fonte: os autores.

Portanto, com base nos achados das etapas operacionalizadas na pesquisa, confirma-se a H1. Nesse sentido, as variáveis estudadas (LL, LA e FCO) são estatisticamente significativas e positivamente relacionadas com o preço das ações das companhias abertas, conforme o esperado. Por outro lado, quando se realiza a análise da relevância dos valores positivos para as variáveis, observa-se que somente o LL 
apresenta maior poder explicativo; as demais variáveis, ao contrário, perdem o poder de explicação. Assim, não se pode confirmar completamente a H2.

A correlação entre as variáveis LL e FCO foi de 0,5629. Já a correlação entre o LL e o LA foi de 0,7757. A correlação entre o FCO e o LA foi de 0,5345. Assim, nota-se que as variáveis estão altamente correlacionadas, razão pela qual não foi utilizada uma regressão múltipla com as três variáveis neste trabalho para o estudo do comportamento das variáveis.

\section{CONCLUSÃO}

Neste trabalho teve-se por objetivo verificar se o comportamento das variáveis contábeis é capaz de explicar o comportamento do preço das ações. Neste estudo foi verificada a relevância da informação contábil para o mercado brasileiro de capitais por meio das variáveis contábeis Lucro Líquido, Fluxo de Caixa Operacional e Lucro Abrangente.

Para atingir tal objetivo, analisou-se a relevância isolada de cada uma das variáveis e o conteúdo informacional de cada variável em relação ao preço da ação. Essa análise foi feita utilizando-se de três modelos de regressão, cada um deles considerando apenas a variável dependente (Preço da Ação) e uma das três variáveis independentes estudadas. Os modelos apresentados para as variáveis independentes LL, LA e FCO mostraram-se estatisticamente significativos ao nível de 1\% no mercado brasileiro de ações.

Para a amostra total, constatou-se maior relevância da informação contábil para o modelo que utiliza LL como variável independente ( $\mathrm{R}^{2}$ ajustado de $39,77 \%$ ). Em segundo lugar, a variável mais value relevant foi o LA ( $\mathrm{R}^{2}$ ajustado de $\left.30,27 \%\right)$. Por fim, o modelo que utilizou o FCO como variável independente foi o menos relevante de todos ( $\mathrm{R}^{2}$ ajustado de $26,24 \%$ ).

Observa-se, portanto, maior relevância do LL para o mercado brasileiro de ações. Isso pode estar alinhado ao fato de que, tradicionalmente, nos países code-law, como é o caso do Brasil, o lucro atende a diversas demandas, isso pode justificar maior interesse dos usuários (investidores) por essa medida de desempenho, em comparação aos demais indicadores analisados.

Além disso, pode-se inferir que o LA se mostra menos relevante, em relação ao LL para o contexto brasileiro por conter informações mais voláteis, principalmente em razão de ajustes a valor de mercado, afetando a capacidade de projeção do fluxo de caixa no longo prazo. Seguindo essa mesma lógica, o mercado de capitais brasileiro, 
de maneira geral, considera o FCO menos relevante em decorrência da menor capacidade dessa informação predizer os fluxos de caixa futuros (MALACRIDA, 2009).

Em um segundo momento, foi feita uma análise dos resultados positivos de cada uma das variáveis estudadas. Os achados apontam que apenas o LL se mostrou mais relevante, quando se consideram somente os resultados positivos. Para o LA e o FCO ocorre o contrário, ou seja, os resultados apresentam menor poder explicativo. Isso reforça a ideia de maior relevância do LL para o contexto brasileiro, em detrimento de outras variáveis. Em relação à amostra em que as empresas apresentam LL diferente de LA, todas as variáveis contábeis são estatisticamente significativas ao nível de $1 \%$. Nesse caso, também foi confirmado que o LL ( $\mathrm{R}^{2}$ ajustado de 42,29\%) é mais relevante para o mercado de capitais em relação às demais variáveis. O LA se apresentou mais relevante ( $\mathrm{R}^{2}$ ajustado de $30,45 \%$ ) que o FCO ( $\mathrm{R}^{2}$ ajustado de $29,55 \%$ ).

Contudo, para a amostra composta de resultados positivos, apesar de confirmar que o $\mathrm{LL}$ ( $\mathrm{R}^{2}$ ajustado de 47,84\%) é mais relevante para o mercado de capitais em relação às demais variáveis, o FCO se apresentou mais relevante ( $\mathrm{R}^{2}$ ajustado de $26,4 \%$ ) que o LA ( $\mathrm{R}^{2}$ ajustado de $24,2 \%$ ). Nesse sentido, observa-se que os investidores consideram que os prejuízos são temporários, entretanto essa percepção não é válida para o LA e o FCO, os quais apresentaram poder explicativo menor para os resultados positivos. Isso pode estar associado ao fato de que o mercado brasileiro não percebe o LA e o FCO positivos. Dessa forma, não se pode afirmar que o mercado considera o LA e o FCO mais value relevant quando se analisam somente os valores positivos, revelando a primazia do LL em relação às demais variáveis. Resultado semelhante foi constatado no estudo de Habib (2010), no mercado australiano, ao comparar a relevância da receita quando as empresas reportam prejuízos.

Os resultados para a relevância das informações contábeis são corroborados pelos estudos de Dhaliwal, Subramanyam e Trezevant (1999), de Kanagaretnam, Mathieu e Shehata (2009) e de Ebaid (2012), cujos achados apontam para maior relevância do Lucro Líquido em relação ao Lucro Abrangente. Adicionalmente, os resultados do presente estudo também se alinham às conclusões encontradas por Malacrida (2009), Silva, Macedo e Marques (2012) e Silva, Macedo e Marques (2013), os quais indicam maior relevância do Lucro Líquido em relação ao Fluxo de Caixa Operacional.

Em relação aos resultados positivos para a informação contábil, os achados apontam para maior relevância do Lucro Líquido, demonstrando menor associação dos prejuízos com o preço das ações, em linha com os resultados de Hayn (1995), Habib e Azim (2008), Beisland (2009) e Filip e Raffournier (2010). Porém, este não se aplica à análise do Fluxo de Caixa Operacional e do Lucro Abrangente. 
Assim, este trabalho contribui para o avanço dos estudos de value relevance, por utilizar essas três variáveis contábeis, comparando-as, além de levantar a questão do poder informacional dos resultados positivos e negativos. O estudo do Lucro Abrangente também é uma contribuição, visto que foram feitas análises trazendo os Outros Resultados Abrangentes para discussão.

Cabe ressaltar que as conclusões alcançadas não podem ser generalizadas, dado que o processo de amostragem é não probabilístico. Futuras pesquisas podem encarregar-se de comparar a relevância de outras variáveis contábeis para a formação do preço da ação no mercado brasileiro de capitais, além de aprofundar a análise da questão dos resultados positivos e negativos das variáveis estudadas.

\section{REFERÊNCIAS}

BALL, R.; BROWN, P. An empirical evaluation of accounting income numbers. Journal of Accounting Research, v. 6, p. 159-177, 1968.

BARTH, M. E.; BEAVER, W. H.; LANDSMAN, W R. Relative valuation roles of equity book value and net income as a function of financial health. Journal of Accounting and Economics, v. 25, p. 1-34, 1998.

BARTH, M. E. et al. The relevance of the value relevance literature for financial accounting standard setting: another view. Journal of Accounting and Economics, v. 31, p. 77-104, 2001.

BEAVER, W. H. The Information Content of Annual Earnings Announcements. Journal of Accounting Research, v. 6, p. 67-92, 1968. (Issue Empirical Research in Accounting Selected Studies).

BEISLAND, L. A. A Review of the Value Relevance Literature. The Open Business Journal, v. 2, p. 7-27, 2009.

BROOKS, C. Introductory econometrics for finance. Cambridge: Cambridge University Press, 2002.

BURGSTAHLER, D.; DICHEY, I. Earnings, adaptation, and firm value. The Accounting Review, v. 72, i. 2, p. 187-215, Apr. 1997.

CHAMBERS, D. et al. An evaluation of SFAS No. 130 comprehensive income disclosures. Review of Accounting Studies, v. 12, p. 557-593, 2007. 
COLLINS, D.; MAYDEW, E. L.; WEISS, L. Changes in the value relevance of earnings and book value over the past forty years. Journal of Accounting and Economics, v. 24, p. 39-67, 1997.

COMISSÃO DE VALORES MOBILIÁRIOS. Demonstrações Financeiras Padronizadas. Disponível em: <http://www.cvm.gov.br/z. Acesso em: 19 mar. 2015.

COMITÊ DE PRONUNCIAMENTOS CONTÁBEIS. CPC 00 (R1). Estrutura Conceitual para Elaboração e Divulgação de Relatório Contábil-Financeiro. 2011a. Disponível em: <http://static.cpc.mediagroup.com.br/Documentos/147_ CPC00_R1.pdf>. Acesso em: 19 mar. 2015.

COMITÊ DE PRONUNCIAMENTOS CONTÁBEIS. CPC 26 (R1). Apresentação das demonstrações contábeis. 2011b. Disponível em: <http://static.cpc.mediagroup.com.br/Documentos/312_CPC_26_R1_rev\%2006.pdf > . Acesso em: 19 mar. 2015.

CORRAR, L. J.; PAULO, E.; DIAS FILHO, J. M. Análise Multivariada para os cursos de Administração, Ciências Contábeis e Economia. 1. ed. São Paulo: Atlas, 2007.

CURCINO, G. M.; LEMES, S.; BOTINHA, R. A. Efeito do Resultado Abrangente nos Indicadores de Desempenho das Companhias Abertas Brasileiras. Revista Evidenciação Contábil \& Finanças, João Pessoa, v. 2, n. 3, p. 24-40, set./dez. 2014.

DHALIWAL, D; SUBRAMANYAM, K. R; TREZEVANT, R. Is comprehensive income superior to net income as a measure of firm performance? Journal of Accounting and Economics, v. 26, p. 43-67, 1999.

EBAID, I. E. The value relevance of accounting-based performance measures in emerging economies. Management Research Review, v. 35, i. 1, p. 69-88, 2012.

FÁVERO, L. P. Análise de dados - modelagem multivariada para a tomada de decisões. Rio de Janeiro: Campus: Elsevier, 2009.

FILIP, A.; RAFFOURNIER, B. The value relevance of earnings in a transition economy: The case of Romania. The International Journal of Accounting, v. 45, p. 77-103, 2010.

FINANCIAL ACCOUNTING STANDARDS BOARD. SFAS 130 - Reporting Comprehensive Income. Norwalk: June, 1997. 
GIL, A. C. Como elaborar projetos de pesquisa. 5. ed. São Paulo: Atlas, 2010.

GUJARATI, D. Econometria Básica. 4. ed. Rio de Janeiro: Campus: Elsevier, 2006.

HABIB, A.; AZIM, I. Corporate governance and the value-relevance of accounting information: evidence from Australia. Accounting Research Journal, v. 21, i. 2, p. 167-194, 2008.

HABIB, A. Value relevance of alternative accounting performance measures: Australian evidence. Accounting Research Journal, v. 23, n. 2, p. 190-212, 2010.

HAYN, C. The information content of losses. Journal of Accounting and Economics, v. 20, p. 125-153, 1995.

HOLTHAUSEN, R. W.; WATTS, R. L. The relevance of value relevance literature for financial accounting standard setting. Journal of Accounting and Economics, v. 31, p. 3-75, 2001.

INTERNATIONAL ACCOUNTING STANDARDS BOARD. Discussion Paper DP/2013/1. A review of the conceptual framework for financial reporting. July 2013.

INTERNATIONAL ACCOUNTING STANDARDS BOARD. IAS 1 - Presentation of Financial Statements, 2011.

KABIR, M. H.; LASWAD, F. Properties of net income and total comprehensive income: New Zea-land evidence. Accounting Research Journal, v. 24, i. 3, p. 268289, 2011.

KANAGARETNAM, K.; MATHIEU, R.; SHEHATA, M. Usefulness of comprehensive income reporting in Canada. Journal of Accounting and Public Policy, v. 28, i. 4, p. 349-365, 2009.

LEE, C.; PARK, M. S. Subjectivity in fair-value estimates, audit quality, and informativeness of other comprehensive income. Advances in Accounting, incorporating Advances in International Ac-counting, i. 29, p. 218-231, 2013.

LOPES, A. B.; MARTINS, E. Teoria da Contabilidade: uma nova abordagem. São Paulo: Atlas, 2014. 
MACEDO, M. A. S. et al. Análise do impacto da substituição da DOAR pela DFC: um estudo sob a perspectiva do value-relevance. Revista de Contabilidade e Finanças, v. 22, i. 57, p. 299-318, set./dez. 2011.

MACEDO, M. A. S.; ROMANA, T. D.; SILVA, J. C. Q. Análise dos Determinantes da Relevância das Informações Contábeis no Brasil: um estudo com base no lucro líquido (LL) e no patrimônio líquido (PL) para o período de 2010 a 2012. In: CONGRESSO USP CONTROLADORIA E CONTABILIDADE, 14., 2014. São Paulo. Anais... São Paulo, 2014.

MADEIRA, F. L.; COSTA JÚNIOR, J. Value Relevance dos outros resultados abrangentes nas companhias abertas brasileiras. In: CONGRESSO ANPCONT, 8., 2014. Rio de Janeiro. Anais... Rio de Janeiro, 2014.

MALACRIDA, M. J. C. A Relevância do Lucro Líquido versus Fluxo de Caixa Operacional para o Mercado de Ações Brasileiro. 2009. 146 p. Tese (Doutorado em Ciências Contábeis)-Universidade de São Paulo, São Paulo, 2009.

MARTINS, E. et al. Manual de contabilidade das sociedades por ações: aplicável a todas as sociedades de acordo com as normas internacionais e do CPC. 2. ed. São Paulo: Atlas, 2013.

MARTINS, G. M.; THEÓPHILO, C. R. Metodologia da Investigação Científica para Ciências Sociais Aplicadas. 2. ed. São Paulo: Atlas, 2009.

NIYAMA, J. K.; SILVA, C. A. T. Teoria da Contabilidade. 2. ed. São Paulo: Atlas, 2011.

NOVAES, P. V. G. Essays On Life Cycle, Voluntary Disclosure And The Cost Of Capital Of Brazilian Companies. Dissertação (Mestrado em Ciências Contábeis)Universidade Federal do Espírito Santo, Vitória, 2015.

NWAEZE, E. T. Regulation and the Valuation Relevance of Book Value and Earnings: Evidence from the United States. Contemporary Accounting Research, v. 15, i. 4, p. 547-573, 1998.

OHLSON, J. A. Earnings, book values, and dividends in equity valuation. Contemporary Accounting Research, v. 11, p. 661-687, 1995.

PINTO, J. A. How comprehensive is comprehensive income? The value relevance of foreign currency translation adjustments. Journal of International Financial Management and Accounting, v. 16, i. 2, p. 97-122, 2005. 
RESS, W. P. Influences on the Value Relevance of Equity and Net Income in the UK. Managerial Finance, v. 25, i. 12, p. 58-65, 1999.

SARLO NETO, A. S. et al. Uma Investigação sobre a Capacidade Informacional dos Lucros Contábeis no Mercado Acionário Brasileiro. In: CONGRESSO USP CONTROLADORIA E CONTABILIDADE, 3., 2003, São Paulo. Anais... São Paulo, 2003.

SILVA, A.; MACEDO, M. A. S.; MARQUES, J. A. V. C. Análise da Relevância da Informação Contábil no Setor Brasileiro de Energia Elétrica no período de 2005 a 2007: uma discussão com foco nas variáveis LL, FCO e EBITDA. Revista Universo Contábil, v. 8, n. 2, p. 6-24, abr./jun. 2012.

SILVA, A.; MACEDO, M. A. S.; MARQUES, J. A. V. C. Análise da Relevância da Informação Contábil no Setor Brasileiro de Energia Elétrica no período de 2005 a 2009: um estudo comparativo entre as informações de lucro e de caixa. Revista Contabilidade Vista \& Revista, v. 24, n. 2, p. 63-90, abr./jun. 2013.

WATTS, R.; ZIMMERMAN, J. Positive accounting theory. Englewood Cliffs: Prentice Hall, 1986.

\section{Como citar este artigo:}

\section{ABNT}

BATISTA, Tayná Cruz; OLIVEIRA, Juliana Ferreira de; MACEDO, Marcelo Alvaro da Silva. Relevância da informação contábil para o mercado brasileiro de capitais: uma análise comparativa entre Lucro Líquido, Lucro Abrangente e Fluxo de Caixa Operacional. RACE, Revista de Administração, Contabilidade e Economia, Joaçaba: Ed. Unoesc, v. 16, n. 1, p. 381-408, jan./abr. 2017. Disponível em: <http:// editora.unoesc.edu.br/index.php/race>. Acesso em: dia/mês/ano.

\section{APA}

Batista, T. C., Oliveira, J. F. de, \& Macedo, M. A. da S. (2017). Relevância da informação contábil para o mercado brasileiro de capitais: uma análise comparativa entre Lucro Líquido, Lucro Abrangente e Fluxo de Caixa Operacional. RACE, Revista de Administração, Contabilidade e Economia, 16(1), 381-408. Recuperado em dia/mês/ ano, de http://editora.unoesc.edu.br/index.php/race 
